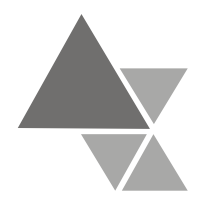

\title{
Adesão ao Programa de Alimentação Escolar por Alunos de Instituições Públicas de Ensino no Município de Toledo, PR.
}

\author{
Rozane Aparecida Toso Bleil ${ }^{1}$, Elisabete Salay $^{2}$, Marina Vieira da Silva ${ }^{3}$
}

O Programa Nacional de Alimentação Escolar (PNAE) tem como um de seus objetivos oferecer uma refeição que mantenha a criança alimentada durante a jornada de aula. Um dos problemas que pode prejudicar o alcance dos objetivos nutricionais do programa relaciona-se à sua adesão pelos escolares. Os objetivos do presente estudo foram conhecer a adesão dos alunos ao programa de alimentação escolar, assim como os fatores que podem interferir no consumo dos alimentos oferecidos. Para tanto foi realizada, no ano de 2004, uma pesquisa com 167 alunos do ensino fundamental II de amostra de escolas públicas no município de Toledo - PR. Os resultados mostraram expressiva (77\%) adesão dos alunos ao programa e destes, $57 \%$ referiram consumir a alimentação escolar de 4 a 5 vezes na semana. Não foi captada associação estatisticamente significativa entre a adesão ao PNAE e as variáveis escolaridade materna, renda familiar e estado nutricional do aluno. Em relação aos fatores que interferem na adesão ao programa, nota-se que algumas preparações oferecidas no cardápio escolar são pouco apreciadas (preparações doces, tipo prato único e sopas). Na opinião da maioria dos alunos, as condições de distribuição da alimentação escolar, com exceção da temperatura do alimento, são adequadas. Entretanto, alguns aspectos podem ser melhorados a fim de contribuir para maior adesão ao programa, em especial aqueles que promovam mudanças no tipo de alimento oferecido e no local para realização das refeições.

Palavras-chave: alimentação escolar, consumo de alimentos, adolescente.

One of the National School Lunch Program goals is to offer meals that will sustain the student during the whole period he or she remains at school. But, the students' adhesion to such food program is one of the problems to reach the program nutritional goal. This paper aims at identifying the students' adhesion to the school lunch program as well as the aspects that determine its consumption. A research was carried out with 167 elementary school students $\left(5^{\text {th }}\right.$ to $8^{\text {th }}$ grades) of public schools in Toledo-PR, in 2004. The results have shown expressive adhesion of the students to this program (77\%). From those, $57 \%$ consumed school food 4 to 5 times per week. It was not identified a significant association between the family income, maternal education level and nutritional status and the adhesion to the school lunch program. It was observed that some options offered in the school menu are less acceptable (sweet options, single items and soup). In general, the students considered the meal distribution conditions adequate, except the food temperature. However, some aspects can be improved in order to contribute to a greater adhesion to the program, specially those ones that will promote changes in the food offered and in the place where the meals will be served.

Key-words: school lunch, food consumption, adolescent.

\footnotetext{
${ }^{1}$ Doutora em Alimentos e Nutrição, FEA/DEPAN/UNICAMP. Docente da Faculdade Assis Gurgacz - FAG, Cascavel - PR. Endereço: Rua Riachuelo, 2488/7, Jardim Independência, Cascavel -PR. CEP 85813-310.Fone: (45) 3037 4002,

E-mail: hrbleil@certto.com.br

${ }^{2}$ Professora Livre - Docente da FEA/UNICAMP, Campinas - SP.

${ }^{3}$ Professora Doutora ESALQ/USP,Campus de Piracicaba-SP.
} 


\section{Introdução}

O Programa Nacional de Alimentação Escolar - PNAE foi implementado no Brasil em meados da década de 50 , e é reconhecido como um dos mais antigos programas sociais do governo federal. Inicialmente teve como meta atender os alunos relativamente mais pobres da Região Nordeste, por meio de doações de leite em pó proveniente do excesso da produção americana. Findos os estoques, o governo brasileiro assumiu a responsabilidade pela continuidade ao programa. Em 1955, o programa de alimentação escolar foi regulamentado pelo governo federal e destacou entre os objetivos, a melhoria das condições nutricionais das crianças e a redução dos índices de evasão e repetência, com melhoria no rendimento escolar ${ }^{[1]}$.

A trajetória da implantação do PNAE no Brasil é descrita de forma pormenorizada nos trabalhos de Sturion ${ }^{[2]}$, Stolarski ${ }^{[3]} \mathrm{e}$ Nogueira ${ }^{[4]}$.

Atualmente o PNAE apresenta como objetivo principal, oferecer uma refeição que mantenha a criança alimentada durante $o$ período em que a mesma permanece na escola, a fim de garantir a concentração necessária à aprendizagem. Uma das metas do PNAE é fornecer em torno de $15 \%$ das necessidades nutricionais dos alunos de ensino fundamental [5]. Cabe destacar ainda que o referido programa não é responsável pela eliminação dos problemas complexos, como a desnutrição e o fracasso escolar ${ }^{[6]}$.

Em 1985, Lima ${ }^{[7]}$ enfatizou que a alimentação escolar deveria "ser vista como algo natural e integrado ao ambiente escolar e cujo objetivo fosse satisfazer as necessidades fisiológicas do organismo, no período em que o aluno permanece na escola”.

Em países desenvolvidos como os Estados Unidos, Canadá, França, Inglaterra e Japão, o Estado tem o dever de oferecer alimentação escolar no período em que as crianças permanecem na escola ${ }^{[8]}$. Stolarski ${ }^{[3]}$ destaca que o referido programa nestes países não registra objetivos assistencialistas. Porém, nos países em desenvolvimento, face às dificuldades econômicas, a alimentação escolar ainda assume esse papel ${ }^{[1,9]}$. Em muitos países da América Latina, a implementação da alimentação escolar tem contribuído para reduzir o absenteísmo, aumentar o número de alunos que freqüentam as instituições de ensino e ainda, tem levado os pais a decidirem por manter seus filhos na escola $^{[10]}$.

Cabe enfatizar também que a alimentação escolar deve ser planejada de forma a contribuir para a prevenção de distúrbios nutricionais que possam trazer como conseqüência o aumento da prevalência de doenças crônicas não transmissíveis ${ }^{[11,12]}$.

Stolarski ${ }^{[3]}$ destaca a necessidade da inclusão de conteúdos didáticos de educação nutricional nas unidades de ensino de todo o país, para que seja possível orientar e prevenir problemas de sobrepeso, transtornos alimentares e outras doenças relacionadas à alimentação inadequada. Em relação a esta temática, destacam-se os estudos realizados por Sturion et al. ${ }^{[13]}$, Martins et al. ${ }^{[14]}$, Zancul ${ }^{[15]}$, Spinelli e Canesqui ${ }^{[16]}$, Caroba ${ }^{[17]}$, Mainardi ${ }^{[18]}$ e Pipitone ${ }^{[19]}$ que avaliaram o e 
também o papel da escola e educadores no que se refere a promoção de educação nutricional.

Outro item a ser analisado é o aspecto econômico do PNAE, pois produtores rurais e comunidade escolar podem ser beneficiados, uma vez que a produção agrícola de pequenos e médios produtores rurais pode contribuir para melhorar a qualidade da alimentação escolar oferecida aos alunos no ambiente escolar ${ }^{[20]}$.

O PNAE é um programa reconhecido entre as diversas políticas sociais no Brasil, porém poucas análises sobre sua atuação têm sido elaboradas ${ }^{[3]}$. Silva ${ }^{[21]}$ e Danelon et al. ${ }^{[22]}$ destacam que o referido programa passou por raríssimas avaliações, a fim de conhecer o seu impacto sobre o estado nutricional dos alunos e sua real cobertura.

A baixa adesão ao programa, conforme constatado pela Pesquisa Nacional sobre Saúde e Nutrição - PNSN, realizada em 1989, parece ter continuado mesmo após o processo de descentralização. Nesse sentido, Sturion et al. ${ }^{[13]}$ referem que são necessários estudos complementares para identificar os problemas e melhorar a adesão ao programa e evitar cortes de investimentos na área.

Ressalta-se que o governo federal disponibiliza ao programa valores monetários inferiores ao executado, cabendo ao município a contrapartida para o custo final da alimentação escolar. De acordo com Pipitone e Gandini ${ }^{[19]}$, a descentralização do programa de alimentação escolar que ocorreu em 1994, foi um marco na história do PNAE. Com ela, era esperada melhoria na adesão às refeições, uma vez que a incorporação de alimentos in natura, o atendimento dos hábitos alimentares dos escolares e a diversificação do cardápio poderiam estimular o consumo das preparações. Também seria possível a redução nos custos dos produtos, devido às parcerias com produtores locais de alimentos ${ }^{[19]}$.

Face ao exposto, esta pesquisa pretende conhecer a adesão dos alunos ao programa e identificar os fatores que podem interferir no consumo da alimentação escolar oferecida aos alunos do município de ToledoPR.

\section{Metodologia}

Foi realizado um estudo transversal de caráter quantitativo conforme classificação relatada por Minayo ${ }^{[23]}$, envolvendo pesquisa de campo, tendo por base uma amostra de escolares adolescentes matriculados no ensino fundamental II (5 a a $8^{\underline{a}}$ séries), do município de Toledo-Paraná. O referido município está localizado na região oeste do estado do Paraná e ocupa uma área de $1.197 \mathrm{~km}^{2}$. Em 2004 a população total era de 104.332 habitantes e destes, 85.911(82,34\%) residiam na área urbana do município. A principal fonte de renda deriva-se da agricultura, onde os produtos estão vinculados em sua maioria às atividades das agroindústrias.

Os dados da presente pesquisa integram o projeto "Contrastes regionais nos custos, qualidade e operacionalização do Programa Nacional de Alimentação Escolar PNAE e seu impacto nos padrões alimentares da população brasileira”, financiada pelo CNPq (processo $\mathrm{n}^{\mathrm{o}}$ 504369/2003-2). A pesquisa foi aprovada pelo Comitê de Ética em Pesquisa com Seres Humanos da Faculdade de Odontologia de Piracicaba (Processo $n^{0}$ 099). Os alunos foram devidamente esclarecidos 
sobre o objetivo e procedimentos da pesquisa, os quais encaminharam os Termos de Consentimento Livre e Esclarecido (TCLE) aos pais ou responsáveis.

Para a definição da população de estudo, foi utilizada a amostra probabilística, ou seja, as unidades de ensino foram sorteadas de maneira que a probabilidade de uma escola ser incluída na amostra fosse proporcional ao seu número de alunos. Para isso foi elaborada uma tabela, acumulando o número de alunos, de maneira que cada escola foi associada a um intervalo de valores da frequiência acumulada de alunos. As escolas que integraram a amostra foram sorteadas respeitando a probabilidade em função do número de alunos e não da localização geográfica das mesmas. Ao final foi estabelecido que 4 (quatro) das 26 (vinte e seis) escolas da rede de ensino fundamental II fizessem parte da amostra, sendo constituído de 3 (três) escolas da periferia e 1 (uma) escola da área rural. Cabe esclarecer que na distribuição das escolas em áreas de abrangência, a Secretaria Municipal de Educação divide as escolas entre central (3 unidades), periferia (12 unidades) e zona rural
(11 unidades). Sendo assim, a probabilidade de uma escola central ter sido incluída na amostra foi pequena. Outro aspecto a ser considerado nas análises do resultado em relação à distribuição das escolas é que mesmo sendo definidas como área rural, estas instituições de ensino estão localizadas em pequenas comunidades (distritos) pertencentes ao município de Toledo-PR.

Após a seleção das escolas, passou-se a etapa de definição do número de alunos que integrariam a amostra em cada uma das unidades de ensino. Optou-se por não excluir qualquer classe das distintas séries escolares, a fim de contemplar todas as faixas de idade dos escolares. Em cada uma das unidades selecionadas e para cada série a amostra final incluiu três alunos de cada uma das séries mantidas pela escola (exceto para o período noturno, devido às dificuldades para a coleta de dados). Ao final integraram a amostra 167 alunos. Cabe registrar que o sorteio dos mesmos foi realizado em sala de aula, com auxílio da lista de frequiência adotada pelos professores. A Tabela 1 mostra o número de alunos participantes da amostra.

Tabela 1. Número de alunos participantes da pesquisa de acordo com a unidade de ensino de origem. Toledo - PR, 2004.

\begin{tabular}{llccc}
\hline \multicolumn{1}{c}{ Unidade de ensino } & Localização & $\begin{array}{c}\text { Total de alunos } \\
(\boldsymbol{n}) *\end{array}$ & $\begin{array}{c}\text { Séries } \\
(\boldsymbol{n})\end{array}$ & $\begin{array}{c}\text { Alunos } \\
\text { integrantes da } \\
\text { amostra }(\boldsymbol{n})\end{array}$ \\
\hline Escola Estadual A & Periferia & 573 & 18 & 56 \\
Escola Estadual B & Periferia & 273 & 11 & 31 \\
Escola Estadual C & Periferia & 723 & 19 & 57 \\
Escola Estadual D & Área rural & 222 & 8 & 23 \\
\hline Total & 4 & 1.791 & 56 & 167 \\
\hline
\end{tabular}

*Dados obtidos junto ao Núcleo regional de Educação do Município de Toledo - Paraná. 2004.

Os dados socioeconômicos das famílias dos alunos, informações sobre a idade dos pais/responsáveis, escolaridade, rendimentos familiares, acesso aos programas sociais governamentais e questões relativas ao programa de alimentação escolar, foram obtidos por meio de questionário auto- 
aplicado, o qual foi entregue ao aluno para ser levado até os pais, juntamente com uma solicitação para que a devolução fosse efetuada no prazo de 3 dias.

Para a construção do banco de dados com registro das referidas informações utilizou-se o software Excel (Microsoft Excel, 2000).

Foi realizada a avaliação antropométrica de todos os alunos integrantes da pesquisa, sendo priorizadas medidas de peso e estatura. Esse método é muito utilizado devido à praticidade, baixo custo operacional e simplicidade no treinamento do pessoal auxiliar. O Índice de Massa Corpórea - IMC por idade foi utilizado para a avaliação nutricional, com o objetivo de analisar a situação nutricional atual dos adolescentes. Estudos recentes reconhecem que o IMC é um método adequado para a avaliação do estado nutricional de crianças e adolescentes, tanto para o diagnóstico de baixo peso quanto do excesso de peso ${ }^{[24]}$.

As análises do IMC no presente estudo foram elaboradas com base nos critérios propostos por Must et al. ${ }^{[25]} \mathrm{e}$ preconizados pela Organização Mundial da Saúde - OMS ${ }^{[26]}$. Para tanto, foram adotados os seguintes intervalos: IMC $<5^{\circ} \mathrm{P}$ (baixo peso), $5^{\circ} \mathrm{P} \leq \mathrm{IMC}<85^{\circ} \mathrm{P}$ (eutrofia), $85^{\circ} \mathrm{P} \leq$ $\mathrm{IMC}<95^{\circ} \mathrm{P}$ (sobrepeso) e IMC $\geq 95^{\circ} \mathrm{P}$ (indicativo de obesidade).

Para a análise da adesão à alimentação escolar, foi utilizado um questionário próprio, elaborado com base nos instrumentos desenvolvidos por Oetterer et al. ${ }^{[27]}$ e Sturion ${ }^{[2]}$, o qual foi aplicado aos alunos na forma de entrevista individual. $\mathrm{O}$ instrumento reuniu questões sobre: a) adesão dos escolares ao PNAE; b) preferências dos alunos em relação ao tipo de preparações oferecidas pelo programa; c) opinião dos mesmos sobre as condições de distribuição das refeições e d) questões relativas às cantinas escolares.

A adesão foi analisada por meio da percentagem de adesão ao programa, utilizando-se o cálculo do Índice de Atendimento Efetivo - IAE (\%IAE = total de alunos atendidos/total de alunos presentes na escola x 100), conforme proposto por Gandra \& Gambardella ${ }^{[28]}$. Para as análises foram consideradas proporções classificadas em quatro categorias de atendimento: alto (acima de 70\%), médio (50 a 70\%), baixo (30 a 50\%) e muito baixo (menor que $30 \%{ }^{[2]}$. Outra análise da adesão foi realizada por meio de freqüência de consumo da alimentação escolar, sendo considerada adesão efetiva ao programa o consumo de alimentos de quatro a cinco vezes na semana ${ }^{[13]}$.

A aceitabilidade foi medida com base nas preferências alimentares as quais foram analisadas em relação às seis refeições mais freqüentemente servidas nas unidades integrantes da amostra, e representaram a totalidade dos cardápios oferecidos: 1) preparação tipo almoço; 2) lanche com suco; 3) sopa; 4) prato único; 5) preparação doce e 6) lanche com leite. Para tanto, consideraramse as refeições preparadas com maior frequiência (duas a quatro vezes ao mês), conforme verificado nas planilhas de preparações disponíveis nas escolas. Nesta análise foi utilizado o teste afetivo de preferência, por meio da escala hedônica facial [29], que mostra o quanto o aluno gosta ou 
desgosta de determinado alimento ou preparação.

Em relação à opinião dos alunos sobre condições de distribuição das refeições, foram analisados os seguintes itens: local, temperatura, tempo destinado à alimentação e utensílios usados na alimentação escolar.

Destacam-se ainda as questões formuladas em relação ao consumo de alimentos na cantina escolar, quando mantida na unidade de ensino (frequiência, tipo de produto adquirido e motivos pelos quais os alunos compravam produtos na cantina) e em outros locais, para serem consumidos na escola.

O banco de dados foi construído no programa EpiData e para as análises utilizouse o programa EpiInfo (2000) e Statistical Package for the Social Sciences - SPSS for Windows (2003). Foram realizadas análises descritivas e aplicado o teste de qui-quadrado comum, com nível de significância de 5\%. Esse teste é aproximado e de acordo com Cochran ${ }^{[30]}$, a aproximação só é satisfatória para tabelas de contingência nas quais o número de colunas ou de linhas seja pelo menos maior que 2. Nesse caso devem ser obedecidas as seguintes condições: a freqüência esperada mínima não pode ser menor do que 1 e no máximo, 20\% das frequiências esperadas podem ser menores do que 5.

\section{Resultados e discussão}

Em 2004, os dados da Secretaria Municipal de Educação mostraram que no ensino fundamental II foram matriculados 8187 alunos nas 26 escolas pertencentes ao município de Toledo - PR. Do total, 1587 alunos freqüentavam as escolas centrais, 5539 alunos estudavam em escolas localizadas na periferia e 1061 alunos estavam matriculados em escolas na área rural.

Em Toledo, o modelo de gestão escolar é municipalizado. Todos os gêneros alimentícios necessários são adquiridos pela Prefeitura Municipal, por meio da Coordenação do Programa Municipal de Alimentação Escolar - PMAE e a sistemática de compra empregada é a licitação. A entrega dos alimentos não perecíveis às escolas é realizada pelos funcionários da Prefeitura e dos demais, diretamente pela empresa selecionada por meio de licitação. O preparo e a distribuição da alimentação escolar são realizados na forma de auto-gestão, diretamente nas escolas. O cardápio é proposto por profissional responsável (Nutricionista) pelo programa no município e reformulado mensalmente, tendo cada escola a liberdade de escolher o dia para o preparo de cada cardápio.

\section{Análise das condições sócio- econômicas das famílias}

Dos 167 questionários sócioeconômicos enviados aos pais ou responsáveis, $24 \%$ não foram respondidos. $\mathrm{O}$ estudo revela que o responsável masculino pelo adolescente geralmente é o pai (80\%), com média de idade de 42 anos, sendo que um terço deles $(37 \%)$ possui o ensino fundamental I incompleto. O rendimento mensal médio ${ }^{4}$ dos pais que trabalhavam na época da pesquisa (82\%) era de $\mathrm{R} \$ 667,80$ e destes, $46,9 \%$

\footnotetext{
${ }^{4}$ Cabe destacar que para as análises, foi considerado apenas o rendimento recebido na forma de salário. $\mathrm{Na}$ época da pesquisa, o salário-mínimo (SM) correspondia a $\mathrm{R} \$ 260,00$.
} 
recebiam entre um e dois salários-mínimos. Com relação ao responsável feminino, na maioria das situações é a mãe (94\%), com média de idade de 39 anos e a escolaridade prevalente também foi o ensino fundamental I incompleto $(43,2 \%)$. A renda mensal média totalizou R\$ 442,20 e $35,7 \%$ das mulheres obtinham até um salário-mínimo. Destaca-se ainda que, na época da pesquisa, apenas $52,1 \%$ das mães que responderam ao questionário, trabalhavam fora do domicilio.

Aproximadamente um terço (32\%) das famílias avaliadas estava inscrita em algum programa social. Destes, 59\% participavam do programa do governo federal Bolsa-Família, o que mostra a necessidade de complementação do rendimento familiar.

Os responsáveis foram questionados ainda sobre o seu conhecimento em relação à alimentação oferecida aos alunos. Dos pais/responsáveis pelos alunos que responderam à questão $(n=115)$ sobre a alimentação escolar, 94\% a consideraram boa ou muito boa. Em relação ao conhecimento dos pais/responsáveis sobre o consumo da alimentação oferecida pela escola aos seus filhos, 96\% $(n=120)$ registraram que os filhos costumavam comer a alimentação oferecida na escola.

\section{Avaliação do Programa Nacional de Alimentação Escolar}

\subsection{Adesão dos alunos ao PNAE}

No presente estudo, a adesão média dos alunos das quatro escolas em relação ao programa (medido pelo IAE) foi de 77,3\%. Destaca-se que a escola da área rural (escola D) foi a que apresentou a menor adesão ao programa $(72,2 \%)$. Em estudo realizado por Danelon ${ }^{[31]}$ foi verificada adesão ao programa de alimentação escolar em 75,3\% dos escolares de Campinas-SP, semelhante aos resultados encontrados em Toledo - PR.

É possível inferir que esta população apresenta maior disponibilidade alimentar no domicílio e que os alunos já chegam à escola tendo ingerido, anteriormente, algum alimento ou trazendo lanches de casa, adquiridos em distintos estabelecimentos. Mesmo sendo uma escola pertencente à área rural, os alunos em sua maioria são filhos de proprietários de terras, que residem em uma comunidade rural e podem apresentar melhores condições socioeconômicas.

Ao analisar a adesão dos alunos em relação à alimentação oferecida na escola por meio da frequiência de consumo, a presente pesquisa revelou que, no município de ToledoPR, aproximadamente $57 \%$ dos alunos referiram consumir a alimentação entre quatro e cinco vezes na semana, sem diferença expressiva entre as escolas. Esse resultado mostra adesão inferior à medida pelo IAE. Cabe destacar que o IAE não é considerado o melhor método para avaliação da adesão dos alunos à alimentação escolar, porém é de fácil aplicação e traz resultados rápidos. Diversos autores destacam que o índice de sobras agregadas (medido pela fórmula: \%aceitação = peso total do alimento distribuído/peso total do alimento produzido x 100) é o método mais adequado para conhecer a aceitação da alimentação em uma população [28], porém esse recurso não foi adotado no presente estudo. Destaca-se ainda nesta pesquisa que a rejeição pela alimentação foi pouco expressiva $(6 \%)$. Entre os alunos que não consomem a 
merenda, a maioria revelou que a principal motivação é o fato de "não apreciarem" as preparações servidas (70\%).

O resultado do presente estudo, em relação à adesão à alimentação oferecida na escola distingue-se do encontrado por Martins et al. ${ }^{[14]}$ no município de Piracicaba - SP, o qual revelou baixa adesão ao programa (45\%). Outra pesquisa com alunos da rede pública de ensino no município de Ribeirão Preto - SP ${ }^{[15]}$ também mostrou que a adesão diária ao programa de alimentação escolar atingiu apenas $14,7 \%$ na rede estadual de ensino, confirmando os resultados de Pecorari ${ }^{[32]}$ que apontou baixa adesão diária ao PNAE no município de Piracicaba - SP (39,3\%).

Chitra e Reddy ${ }^{[33]}$ mostram em sua pesquisa com estudantes entre 10 e 15 anos de diferentes escolas urbanas na Índia, que menos da metade $(43 \%)$ dos alunos tomam o café da manhã oferecido na unidade. Também Sturion et al. ${ }^{[13]}$, identificaram baixa adesão ao programa (apenas 46\% dos escolares consumiam a alimentação oferecida na instituição com maior freqüência). Os autores ressaltam que para a adesão ser classificada como efetiva, os alunos devem consumir a alimentação escolar entre quatro e cinco vezes durante a semana ${ }^{[13]}$.

Cabe destacar que as referidas pesquisas foram realizadas tendo como amostra grupos distintos, com características socioeconômicas diferentes. Porém em estudos desta natureza é importante ter conhecimento sobre os resultados de várias regiões do país, a fim de identificar possíveis fatores que possam interferir na adesão a alimentação escolar e que sejam comuns ao público formado por crianças e adolescentes, os quais constituem o grupo principal a ser atendido pelo programa de alimentação escolar.

A tabela 2 mostra a relação entre os rendimentos familiares com base no valor recebido em forma de salários e a adesão à alimentação escolar baseada no Índice de Atendimento Efetivo.

Tabela 2. Estratos de rendimento salarial e adesão à alimentação escolar pelos alunos do ensino fundamental II. Toledo - PR, 2004.

\begin{tabular}{|c|c|c|c|c|c|c|}
\hline \multirow{3}{*}{$\begin{array}{l}\text { Estratos de } \\
\text { rendimentos }\end{array}$} & \multicolumn{6}{|c|}{ Adesão à alimentação escolar } \\
\hline & \multicolumn{2}{|c|}{ Sim } & \multicolumn{2}{|c|}{ Não } & \multicolumn{2}{|c|}{ Total } \\
\hline & $n$ & $\%$ & $n$ & $\%$ & $n$ & $\%$ \\
\hline Até 260,00 & 10 & $\begin{array}{r}11,0 \\
{[9,8]}\end{array}$ & 1 & $\begin{array}{r}12,5 \\
{[1]}\end{array}$ & 11 & {$[10,8]$} \\
\hline De 260,01 a 520,00 & 25 & $\begin{array}{r}27,0 \\
{[24,5]}\end{array}$ & 3 & $\begin{array}{r}37,5 \\
{[3]}\end{array}$ & 28 & {$[27,5]$} \\
\hline De 520,01 a 780,00 & 19 & $\begin{array}{r}20,0 \\
{[18,6]}\end{array}$ & 1 & $\begin{array}{r}12,5 \\
{[1]}\end{array}$ & 20 & {$[19,6]$} \\
\hline De 780,01 a $1.040,00$ & 19 & $\begin{array}{r}20,0 \\
{[18,6]}\end{array}$ & 1 & $\begin{array}{r}12,5 \\
{[1]}\end{array}$ & 20 & {$[19,6]$} \\
\hline A partir de $1.040,01$ & 21 & $\begin{array}{r}22,0 \\
{[20,5]} \\
\end{array}$ & 2 & $\begin{array}{r}25,0 \\
{[2]}\end{array}$ & 23 & {$[22,5]$} \\
\hline Total & 94 & {$[92,0]$} & 8 & {$[8,0]$} & 102 & {$[100,0]$} \\
\hline
\end{tabular}


Ao analisar a relação entre rendimento familiar e adesão à alimentação oferecida na escola, medida pelo IAE, o presente estudo não captou associação significativa $(p>0,05)$ entre as duas variáveis.

Alguns estudos revelam que o nível socioeconômico elevado contribui para o maior consumo de alimentos com alta densidade energética, alimentos de origem animal, frutas e hortaliças ${ }^{[34,35]}$. Outras pesquisas destacam que conforme aumentam os rendimentos familiares, decresce a proporção de alunos que consome a alimentação escolar ${ }^{[17,35]}$.

Na tabela 3 foi analisada a associação entre escolaridade materna e a frequiência semanal de consumo.

Tabela 3. Escolaridade materna e frequiência semanal de consumo da alimentação escolar pelos os alunos do ensino fundamental II. Toledo - PR, 2004.

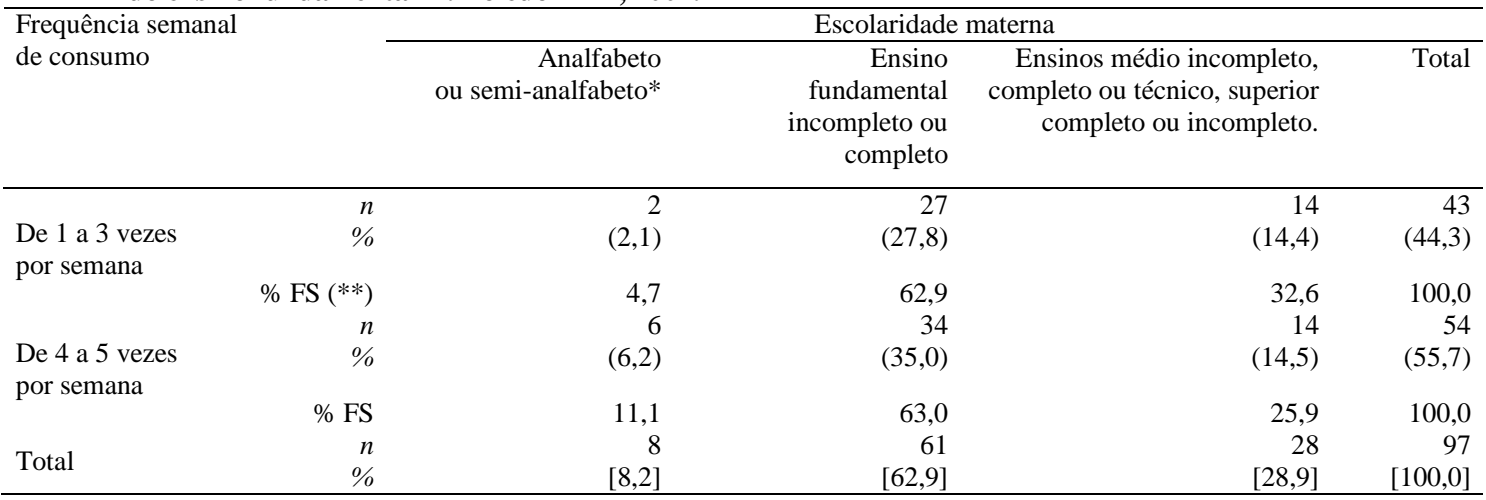

Fonte: pesquisa de campo. 2004.

Teste qui-quadrado: $\chi^{2}=1,58, p=0,45$.

$n=$ número de respostas.

* neste estudo foi considerado semi-analfabeto o indivíduo que sabe ler e escrever, mas nunca frequentou a escola.

Obs.: Os números entre parênteses são os percentuais em relação ao total de escolares $(n=97)$ da amostra.

Os números entre colchetes são os percentuais em relação ao total observado na coluna.

$\mathrm{Na}$ presente pesquisa não foi verificada associação significativa entre a escolaridade materna e a freqüência de consumo da alimentação escolar $(p=0,45)$.

Alguns estudos apontam que a associação entre escolaridade materna e o estado nutricional revelam-se como os melhores indicadores quando comparados com a renda ${ }^{[17,36,37]}$.

As análises em relação ao estado nutricional e a frequiência semanal de consumo da alimentação escolar são mostradas na tabela 4 . 
Tabela 4. Estado nutricional e freqüência semanal de consumo da alimentação escolar pelos alunos do ensino fundamental II. Toledo - PR, 2004.

\begin{tabular}{|c|c|c|c|c|c|}
\hline \multirow[b]{2}{*}{ Frequência semanal de consumo } & & \multicolumn{4}{|c|}{ Estado nutricional } \\
\hline & & Baixo peso & Eutrofia & $\begin{array}{r}\text { Excesso } \\
\text { de peso }\end{array}$ & Total \\
\hline De 1 a 3 vezes por semana & $\begin{array}{r}n \\
\%\end{array}$ & $\begin{array}{r}2 \\
(1,3)\end{array}$ & $\begin{array}{r}59 \\
(37,6)\end{array}$ & $\begin{array}{r}7 \\
(4,5)\end{array}$ & $\begin{array}{r}68 \\
(43,3)\end{array}$ \\
\hline De 4 a 5 vezes por semana & $\begin{array}{r}\% \mathrm{FS}^{*} \\
n \\
\%\end{array}$ & $\begin{array}{r}2,9 \\
6 \\
(3,8)\end{array}$ & $\begin{array}{r}86,8 \\
75 \\
(47,8)\end{array}$ & $\begin{array}{r}10,3 \\
8 \\
(5,1)\end{array}$ & $\begin{array}{r}100,0 \\
89 \\
(56,7)\end{array}$ \\
\hline Total & $\begin{array}{r}\% \text { FS } \\
n \\
\% \\
\end{array}$ & $\begin{array}{r}6,7 \\
8 \\
{[5,1]} \\
\end{array}$ & $\begin{array}{r}84,3 \\
134 \\
{[85,4]} \\
\end{array}$ & $\begin{array}{r}9,0 \\
15 \\
{[9,6]} \\
\end{array}$ & $\begin{array}{r}100,0 \\
157 \\
{[100,0]} \\
\end{array}$ \\
\hline
\end{tabular}

Fonte: pesquisa de campo. 2004.

Teste qui-quadrado: $\chi^{2}=1,19, p=0,55$.

* FS = frequência semanal de consumo.

Obs.: Os números entre parênteses são os percentuais em relação ao total de escolares $(n=157)$ da amostra.

Os números entre colchetes são os percentuais em relação ao total observado na coluna.

Pode-se afirmar que também não foi captada associação significativa entre o estado nutricional dos alunos $(n=157)$ e a freqüência semanal de consumo da alimentação escolar $(p=0,55)$. Cabe ressaltar que o pequeno número amostral em algumas categorias das variáveis explanatórias pode ter contribuído para não ter sido encontrada associação significativa entre as mesmas.

Diversos autores identificaram a existência de associação positiva entre renda, estado nutricional, escolaridade materna e consumo de alimentação escolar. Pesquisa realizada por Caroba ${ }^{[17]}$ revelou associação estatisticamente significativa entre o consumo de alimentação escolar e o estado nutricional de grupo de adolescentes da rede pública de ensino. Em outro estudo envolvendo adolescentes, cujo objetivo foi comparar o estado nutricional e os rendimentos familiares, identificou-se associação positiva entre sobrepeso e obesidade nas classes de maior nível socioeconômico ${ }^{[36]}$. Também no estudo conduzido por Guimarães ${ }^{[37]}$ foi identificada associação positiva entre renda, escolaridade materna e estado nutricional, em especial no que se refere ao sobrepeso.

\subsection{Opinião dos alunos sobre as condições de distribuição das refeições}

Nas escolas que integraram a amostra da pesquisa, o horário em que as refeições eram servidas foi semelhante as demais escolas da rede de ensino, isto é, entre 10:00h da manhã e 15:30h da tarde, com variação de mais ou menos 30 minutos, conforme o número de turmas existentes na unidade escolar. Geralmente as preparações eram simples, doces ou salgadas, que demandavam pouco tempo para o preparo. Neste aspecto cabe destacar o pequeno número de funcionários que atuavam no serviço, sendo que muitas vezes profissionais de outros setores, principalmente do serviço de limpeza, que não receberam treinamento adequado, eram deslocados para auxiliar no preparo e distribuição das refeições. 
Sturion ${ }^{[2]}$ constatou que a baixa adesão ao programa de alimentação escolar se deve a fatores como: oferecimento de preparações inadequadas aos horários de distribuição, problemas de temperatura, tipo de refeição servida que não atende a preferência dos escolares, a qualidade higiênico-sanitária das refeições distribuídas, pouco tempo para consumir a alimentação, local inadequado e desorganização na distribuição das refeições.

A tabela 5 apresenta a opinião dos alunos em relação à alimentação e sua distribuição.

\begin{tabular}{|c|c|c|c|c|c|}
\hline \multirow{2}{*}{\multicolumn{2}{|c|}{$\begin{array}{c}\text { Fatores que interferem na adesão } \\
\text { à alimentação escolar }\end{array}$}} & \multicolumn{3}{|c|}{$\begin{array}{l}\text { Opinião dos alunos em relação à alimentação } \\
\text { oferecida nas escolas }\end{array}$} & \multirow[t]{2}{*}{ Total } \\
\hline & & Adequado & \multirow[t]{2}{*}{ Inadequado } & Não respondeu & \\
\hline \multirow{2}{*}{ Temperatura } & $n$ & 68,0 & & 9,0 & 158,0 \\
\hline & $\%$ & 40,7 & 53,9 & 5,4 & 100,0 \\
\hline \multirow{2}{*}{ Quantidade } & $n$ & 135,0 & 29,0 & 3,0 & 164,0 \\
\hline & $\%$ & 80,8 & 17,4 & 1,8 & 100,0 \\
\hline \multirow{2}{*}{ Local } & $n$ & 105,0 & 62,0 & - & 167,0 \\
\hline & $\%$ & 62,9 & 37,1 & - & 100,0 \\
\hline \multirow{2}{*}{ Talheres } & $n$ & 131,0 & 36,0 & - & 167,0 \\
\hline & $\%$ & 78,4 & 21,6 & - & 100,0 \\
\hline \multirow{2}{*}{ Copos/canecas } & $n$ & 132,0 & 35,0 & - & 167,0 \\
\hline & $\%$ & 79,0 & 21,0 & - & 100,0 \\
\hline \multirow{2}{*}{ Pratos } & $n$ & 138,0 & 29,0 & - & 167,0 \\
\hline & $\%$ & 82,6 & 17,4 & - & 100,0 \\
\hline \multirow{2}{*}{ Tempo } & $n$ & 103,0 & 64,0 & - & 167,0 \\
\hline & $\%$ & 61,7 & 38,3 & - & 100,0 \\
\hline
\end{tabular}

Fonte: pesquisa de campo. 2004.

* Os traços significam que não houve citações pelos alunos.

A temperatura é um item que deve ser avaliado quando se trata da aceitação de determinado alimento, sendo um fator que pode ser adequado às características da preparação alimentar e ao clima. No presente estudo, apenas $41 \%$ dos escolares referiram que a temperatura das preparações servidas é adequada. Por outro lado, a quantidade de alimento oferecido foi considerada suficiente por $81 \%$ dos alunos, resultado que pode ser considerado positivo.
$\mathrm{Na}$ avaliação do local onde a alimentação escolar é servida, destaca-se que $63 \%$ dos alunos o classificaram como confortável. Destes, $37 \%$ não consideraram o local confortável e o principal motivo alegado foi a falta de espaço para todos se acomodarem sentados (42\% das respostas).

De acordo com Stolarski ${ }^{[3]}$, a sala de aula e o pátio são os principais locais onde a alimentação escolar é servida. Deve-se ressaltar que no presente estudo, o pátio foi o 
espaço mais citado pelos alunos para o consumo das preparações. Os escolares geralmente encontram-se em pé ou sentados em ambientes inadequados. As salas de aula são os espaços geralmente destinados às crianças menores (educação infantil e ensino fundamental I).

Em relação aos utensílios, a presente pesquisa mostra que $78,4 \%$ dos alunos aprovam os talheres utilizados na alimentação escolar, $79 \%$ apreciam o uso do copo/caneca e $83 \%$ aceitam o tipo de prato usado para servir os alimentos.

Muitos municípios brasileiros utilizam pratos e canecas de polipropileno para servir a alimentação aos escolares. Com o tempo, esse tipo de material adquire alterações que comprometem a coloração (tornam-se descorados e opacos) e com textura desagradável (pegajosos e arrepiados). No Paraná, pesquisa desenvolvida por Stolarski [38], destacou o comentário de um secretário municipal de educação que relatou dois fatores que levam a criança à não comer a alimentação escolar: "falta de local adequado para comer o lanche da escola" e a "aparência do prato" e destaca ainda que "os alunos precisam de utensílios e locais de refeições compatíveis com a dignidade humana".

Cabe informar, que no município de Toledo - PR, os pratos e canecas adquiridos pelo programa são confeccionados com material plástico (polipropileno), os quais com o tempo perdem suas características de cor e textura. O tipo de talher usado é a colher (inox) no tamanho "tipo sobremesa".

Martins et al. ${ }^{[14]}$ salientam que os estados e municípios investem poucos recursos em infra-estrutura para o programa de alimentação escolar. Em 2004, a Prefeitura Municipal de Curitiba - PR passou a adotar utensílios de aço inox para a distribuição e consumo da alimentação escolar. Em São Paulo, a Secretaria de Educação incorporou o balcão térmico nas escolas, com objetivo de proporcionar ao próprio aluno o direito de escolher o alimento a ser consumido, a quantidade adequada e também para desenvolver educação nutricional nas escolas [3].

\subsection{Preferências dos alunos em relação ao tipo de preparações oferecidas pelo PNAE}

Cabe destacar que nesta análise foi utilizado o teste afetivo de preferência, por meio da escala hedônica facial. Trata-se de um método muito utilizado em estudos de avaliação de preferência em provadores não treinados, especialmente crianças e adolescentes $^{[29]}$.

O presente estudo revelou que entre as principais preparações oferecidas nas escolas, aquelas que apresentaram menor aceitação pelos alunos foram predominantemente: preparações doces $(41,9 \%)$, tipo prato único $(33,3 \%)$ e sopas $(27,1 \%)$. Nota-se que parcela expressiva dos adolescentes relatou não consumir tais preparações, pelo fato de não gostarem das mesmas. Cabe lembrar que a opção "não gostar" integra a escala hedônica adotada. Assim sugere-se que as referidas preparações ocupem menor espaço no cardápio, com vistas à melhoria da adesão ao programa.

Estudos desenvolvidos por Stolarski ${ }^{[3]}$ e Martins et al. ${ }^{[17]}$ também revelaram maior 
preferência por preparações salgadas. É importante salientar que a sopa dificilmente atinge o conteúdo energético preconizado pelo programa e juntamente com a baixa aceitação verificada, poderia ser uma preparação eliminada do cardápio escolar. Porém a sopa tem sido utilizada com freqüência no cardápio escolar, por ser de fácil preparo e de baixo custo, além de poder incorporar vitaminas e minerais pelo acréscimo de hortaliças, mesmo em dias de altas temperaturas. Assim sendo, é importante a elaboração de análises que envolvam o custo-benefício, uma vez que a manutenção das referidas preparações no cardápio pode gerar desperdício de alimentos e gastos desnecessários.

Cabe salientar que não é possível afirmar que consumir o lanche da escola significa gostar do mesmo. A não apreciação do alimento oferecido pode ter como base diversas causas, entre elas questões culturais, influência dos aspectos sensoriais do alimento (sabor, visual, etc.) e preconceito em relação à alimentação escolar, por esta ser historicamente considerada "comida de pobre". Neste último aspecto, destaca-se a mesma análise elaborada por Martins et al ${ }^{[14]}$ no estudo sobre aceitabilidade da alimentação escolar no ensino público.

\subsection{Consumo de alimentos provenientes das cantinas escolares e outros estabelecimentos}

No município de Toledo, dados da Secretaria Municipal de Educação mostram que a presença de cantina nas escolas públicas é pouco expressiva.

Das escolas que integraram a amostra, apenas em uma delas a cantina funcionava diariamente (escola B), e em outras duas escolas, o funcionamento era restrito a uma vez por semana (escolas A e D) e na escola $\mathrm{C}$ não havia cantina. Ressalta-se que na escola B a população atendida é a que apresentava condição socioeconômica relativamente mais privilegiada, pois atendia alunos de bairro residencial com melhor nível social, ainda que localizada na periferia da cidade.

A presença de vendedores ambulantes no entorno da escola foi observada em apenas delas (escola C), justamente naquela onde não havia cantina. Nota-se que a aquisição de produtos na cantina é uma prática adotada por $58 \%$ dos alunos e destes $33 \%$ referem comprar produtos pelo menos três vezes por semana. Os principais produtos adquiridos pelos alunos são, em ordem decrescente, frituras $(76,3 \%)$, salgadinhos tipo snacks $(49,5 \%)$, balas $(48,5 \%)$, pirulitos $(40,2 \%)$ e refrigerantes $(39,2 \%)$.

As cantinas são espaços que comercializam diversos tipos de alimentos e não existe, de forma geral, preocupação com relação à qualidade dos produtos vendidos e à saúde dos alunos ${ }^{[15]}$.

No Paraná, em 2004 foi aprovada legislação (Lei no 14.423, publicada no DOU em 03 de junho de 2004) que proíbe a comercialização nas cantinas de escolas públicas e particulares, de guloseimas, refrigerantes, frituras, salgadinhos tipo snacks e outros alimentos ricos em "calorias vazias", devendo as mesmas "obedecer a padrões de qualidade nutricional e de vida, indispensáveis a saúde dos alunos" ${ }^{[39]}$. Cabe ressaltar que na época da pesquisa, as escolas ainda se 
encontravam em fase de adaptação à nova legislação estadual e as cantinas ainda comercializavam tais produtos.

Em 2006, a Portaria Interministerial no 1010, de 08 de maio de 2006, estabelece em âmbito nacional as "Diretrizes para a promoção da alimentação saudável nas escolas de educação infantil, fundamental e nível médio das redes públicas e privadas" cujo objetivo é promover e garantir a adoção e práticas alimentares mais saudáveis no ambiente escolar $^{[5]}$.

Zancul ${ }^{[15]}$ destaca em seu estudo que $26,6 \%$ dos alunos das escolas particulares adquirem produtos na cantina diariamente $\mathrm{e}$ nas escolas públicas este dado atinge a proporção média de $7,4 \%$. O presente estudo revela ainda que mesmo consumindo a alimentação oferecida na escola, os alunos compram produtos na cantina (afirmação presente em $44,7 \%$ das respostas válidas). Entre os motivos alegados pelos alunos para adquirirem produtos, destaca-se que $40 \%$ deles compram produtos quando não apreciam a merenda oferecida naquele dia específico. Por outro lado, $45 \%$ dos alunos referiram comprar produtos na cantina mesmo quando consomem o lanche servido na escola.

Oetterer et al. ${ }^{[27]}$ por meio da análise sobre o programa de alimentação escolar, revelaram que $30,5 \%$ dos alunos afirmaram que os alimentos vendidos em cantinas eram melhores que os distribuídos pelo PNAE.

Danelon et al. ${ }^{[22]}$ analisaram alguns aspectos relacionados à alimentação servida no âmbito escolar, a presença de cantinas e a influência destas no comportamento alimentar de adolescentes e apontam que o programa de alimentação escolar deve ser constantemente avaliado para que possa atender as preferências dos escolares e melhorar a adesão ao programa.

Estes resultados causam preocupação, uma vez que a ingestão energética dos alunos pode ser superior às recomendações. Isto contribui para o aumento do sobrepeso e obesidade nesta população. Ainda que na presente pesquisa as prevalências desses distúrbios (9,5\% de excesso de peso) integrem intervalos esperados, é importante manter o grupo em estado de vigilância nutricional, para que as intervenções, se necessárias, sejam adotadas com brevidade. Por outro lado a alimentação escolar pode não atender as preferências dos escolares e assim contribuir para menor adesão ao programa.

\section{Conclusões}

Os resultados do presente estudo revelam que o PNAE é um programa que apresenta boa adesão pelos beneficiários no município de Toledo-PR, pois parcela expressiva $(77 \%)$ dos escolares consome a alimentação escolar e destes, 57\% o fazem com frequiência de 4 a 5 vezes por semana. A renda parece não exercer influência significativa na adesão dos alunos ao programa. Também não foi verificada nesta pesquisa, associação estatisticamente significativa entre a escolaridade materna ou o estado nutricional e a adesão dos alunos ao programa.

$\mathrm{Na}$ opinião dos alunos, alguns aspectos relacionados à alimentação podem ser melhorados. Entre eles, destaca-se a temperatura das preparações, que deveria estar de acordo com o clima e também o tipo de 
cardápio oferecido, que deveria ser elaborado de forma a satisfazer as demandas nutricionais e preferências dos mesmos, uma vez que $77 \%$ deles informaram que não apreciam algumas preparações oferecidas, em especial preparações doces, do tipo prato único e sopas e com isso, é possível evitar o desperdício de recursos.

Embora o local onde a alimentação escolar ocorra não tenha sido considerado inadequado, sugere-se aos gestores públicos a adoção de melhorias do referido espaço, pois comer em pé e em locais insalubres, não condiz com a dignidade humana. A construção de refeitórios simples com mesas e cadeiras pode ser uma alternativa para estimular a maior adesão dos alunos ao programa.

A implantação do sistema self-service, ainda que envolva maior custo, poderia contribuir para estimular a prática da alimentação saudável e propiciar a realização de outras atividades de caráter educativo, por meio da criação de espaço de construção do conhecimento sobre saúde e nutrição.

O presente estudo revelou também que os alunos que adquiriam produtos na cantina, geralmente optavam por alimentos não saudáveis. Destaca-se que no Paraná, bem como em outros estados, a proibição da venda nas cantinas de produtos não saudáveis, pode contribuir para ampliar a adesão ao PNAE.

Cabe ressaltar que se o programa for implementado de modo eficaz, pode ser uma ferramenta fundamental para a promoção da segurança alimentar e nutricional nesta população.

\section{Referências}

[1] Abreu M. Alimentação escolar: combate à desnutrição e ao fracasso escolar ou direito a alimentação da criança e ato pedagógico. Rev. em Aberto 1995; 15(67):1-20.

[2] Sturion GL. Programa de alimentação escolar: avaliação do desempenho em dez municípios brasileiros [tese]. Campinas: Universidade Estadual de Campinas; 2002.

[3] Stolarski MC. Caminhos da alimentação escolar no Brasil: análise de uma política pública no período de 2003-2004 [dissertação]. Curitiba: Universidade Federal do Paraná; 2005.

[4] Nogueira RM. O Programa Nacional de Alimentação Escolar como uma política pública: o caso de Campinas - SP [dissertação]. Campinas: Universidade Estadual de Campinas; 2005.

[5] Brasil. Ministério da Educação. Fundo Nacional de Desenvolvimento da Educação. Brasília: Ministério da Educação/FNDE. 2007 [acessado em 30 de abril de 2007]. Disponível em: http://www.fnde.gov.br/home/index.jsp.arqu ivo=alimentação_escolar/alimentaçãoescolar .html $\neq$ legislação.

[6] Collares C, Moysés MA. Aprofundando a discussão nas relações entre desnutrição, fracasso escolar e merenda. Rev. em Aberto. 1995; 15:67.

[7] Lima GZ. Fracasso escolar: uma questão médica. Cad. CEDES. 1985. 
[8] Collares C, Moysés MA. Fracasso escolar: uma questão médica. Cad. CEDES. 1985.

[9] Andrade MK. Experiências sobre alimentação escolar em países do terceiro mundo (Países com índice de desenvolvimento humano médio). In: Resumos Seminário de Alimentação Escolar. Campinas: ITAL; 1999. p.14-22.

[10] Boschi ME. Alimentação e educação: um direito infantil nas Américas. In: Portal Educacional das Américas. Buenos Aires: Argentina. 2004.

[11] Brasil. Ministério da Educação. Fundo nacional de Desenvolvimento da Educação. Brasília: Ministério da Educação/FNDE. 2006. [acessado em 31 de janeiro de 2006]. Disponível em: http://www.fnde.gov.br/home/index:jspiarq uivo=/alimentacao_escolar/alimentacao_esc olar.html $\neq$ dadosestado.

[12] Pompermayer SR. Alimentação escolar: um estudo sobre a racionalidade [dissertação]. Curitiba: Universidade Federal do Paraná; 2000.

[13] Sturion GL, Silva MV, Ometto AMH, Furtuoso COM, Pipitone MAP. Fatores de adesão dos alunos ao Programa Nacional de Alimentação Escolar no Brasil. Rev. Nutr. 2005; 18(2):167-181.

[14] Martins RCB, Medeiros MAT, Ragonha GM, Olbi JH, Segatti MEP, Osele MR. Aceitabilidade da alimentação escolar no ensino público fundamental. Saúde Rev. 2004; 6(13):71-78.

[15 Zancul MS. Consumo alimentar de alunos nas escolas de ensino fundamental de Ribeirão Preto (SP) [dissertação]. São Paulo: Universidade de São Paulo; 2004.

[16] Spinelli MAS, Canesqui AM. O Programa de Alimentação Escolar no Estado do Mato Grosso: da centralização à descentralização. Rev Nutr. 2002; 15(1):105-117.

[17] Caroba DCR. A escola e o consumo alimentar de adolescentes matriculados na rede pública de ensino [dissertação]. Piracicaba: Escola Superior de Agricultura "Luiz de Queiroz", Universidade de São Paulo; 2002.

[18] Mainardi NA. ingestão de alimentos e as orientações da escola sobre alimentação, sob o ponto de vista do aluno concluinte do ensino fundamental [dissertação]. Piracicaba: Escola Superior de Agricultura “Luiz de Queiróz”, Universidade de São Paulo; 2005.

[19] Pipitone MAP, Gandini RPC. Programa de alimentação escolar: um estudo sobre descentralização, escola e educadores. Saúde Rev. 2001; 3(5-6):33-41.

[20] Paulillo LF, Almeida LM. Redes de segurança alimentar e agricultura familiar: a merenda escolar como instrumento de desenvolvimento local. Rev. Segurança Alimentar e Nutricional. 2005; 12(1): 26-44. 
[21] Silva MV. Alimentação gratuita em creches e escolas de ensino fundamental no Brasil: análise da focalização nos anos $80 \mathrm{e}$ 90. In: Congresso Latinoamericano de Nutrición. Buenos Aires: SLAN; 2000. p. 178 .

[22] Danelon MAS, Danelon MS, Silva MV. Serviços de alimentação destinados ao público escolar: análise da convivência do Programa de Alimentação Escolar e das cantinas. Rev. Segurança Alimentar e Nutricional. 2006; 13(1):85-94.

[23] Minayo MCS. O desafio do conhecimento: pesquisa qualitativa em saúde. São Paulo: Hucitec; 1999.

[24] Center for disease control and prevention (CDC). BMI for children and teens. 2003. [acessado em 11 de julho de 2004] Disponível

em: http://www.cdc.gov/nccdphp/dnpa/bmi/bmif orage.html.

[25] Must A, Dallai GE, Dietz WH. Reference data for obesity: $85^{\text {th }}$ and $95^{\text {th }}$ percentiles of body mass index (wt/ht2) - a correction. Am. J. Clin. Nutr. 1991; 54:773. [26] Cole TJ, Bellizzi MC, Flegal KM, Dietz WH. Establishing a standard definition for a child overweight and obesity worldwide: international survey. Br. Med. J. 2000; 320:1240-1242.

[27] Oetterer M, Silva MV, Pipitone MAP, Ometto AM, Furtuoso COM, Sturion GL. Avaliação do Programa de alimentação
Escolar. Relatório final de pesquisa apresentado a FINEP. Piracicaba: ESALQ; 1999. 365p.

[28] Gandra JR, Gambardella AMD (coord.) Avaliação de Serviços de Alimentação e Nutrição. São Paulo: Sarvier; 1983.

[29] Ferreira VLP, Almeida TCA, Pettinelli MLC, Silva MAAP, Chaves JBP, Barbosa EM. Análise sensorial: testes discriminativos e afetivos. Campinas: SBCTA; 2000. 127p. (Manual Série Qualidade).

[30] Cochran WG. Some methods for strengtheing thr common $\chi^{2}$ testes. Biometrics. 1954; 10:417-451.

[31] Danelon MS. Estado nutricional, consumo alimentar e estilo de vida de escolares de Campinas-SP [dissertação]. Piracicaba: Escola Superior de Agricultura "Luiz de Queiroz", Universidade de São Paulo; 2007.

[32] Pecorari RCF. Uma proposta de inovação no cardápio escolar baseada na avaliação do programa de alimentação escolar de Piracicaba-SP [dissertação]. Araraquara: Universidade Estadual Paulista; 2006.

[33] Chitra U, Reddy R. The role of brekfeast em nutrient intake of urban schoolchildren. Public Health Nutr. 2007; 10(1):55-58.

[34] Minaker LM, McCargar L, Lambraki I, Jessup L, Driezen $\mathrm{P}$, Calengor $\mathrm{K}$, et al. School region socio-economic status and 
geographic locate is associate with food behavior of Ontário and Alberta adolescents. Can. J. Public Health. 2006; 97(5):357-361.

[35] Shi Z, Lien N, Kumar BN, HolmboeOttesen G. Sociodemographic differences in food habits and preferences of school adolescents in Jiangsu Province, China. Eur. J. Clin. Nutr. 2005; 59:1439-1448.

[36] Campos LA, Leite AJM, Almeida PC. Nível socioeconômico e sua influência sobre a prevalência de sobrepeso e obesidade em escolares adolescentes do município de Fortaleza. Rev. Nutr. 2006; 19(5):531-538.

[37] Guimarães LV. Estado nutricional e fatores associados ao sobrepeso em escolares da área urbana de Cuiabá-MT [tese]. Campinas: Universidade Estadual de Campinas; 2001.

[38] Stolarski MC. Avaliação do Programa de Merenda Escolar no estado do Paraná [monografia]. Curitiba: Universidade Federal do Paraná; 2001.

[39] Paraná. Secretaria Estadual de Educação. Fundo Desenvolvimento do Estudante - SEED/FUNDEPAR. 2007. [acessado em 30 de abril de 2008]. Disponível em: www.pr.gov.br/fundepar/02 04 leicantinasudavel pnae html. 